\title{
Correlation of The Vertical Dimension of Occlusion with Anthropometric Measurement of Index Finger
}

\author{
Shafqat Hussain ${ }^{1}$ \\ Nazia Yazdanie ${ }^{2}$
}

\author{
BDS, FCPS \\ BDS, MSc, FCPS, PhD, FICD, FICOI
}

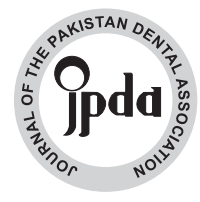

OBJECTIVE: In prosthodontics treatment, the procedure of vertical dimension of occlusion (VDO) recording is considered an essential problem. This procedure is one of the key parameter to be established during the planning of oral rehabilitation; and any error in its recording can affect the prosthodontics treatment severely, and ultimately can lead to disastrous situation. METHODOLOGY: The study was a cross-sectional. A total of 250 patients were taken in the study. The vertical dimension of occlusion was recorded between two points, one on the base of nasal septum and the other on the lower border of chin. Then the length of index finger was measured with digital Vernier caliper.

RESULTS: Vertical dimension of occlusion is significantly correlated with the index finger. The correlation of VDO with index finger in males and females was significant $(r=0.74$ and $r=0.82$ respectively, $\mathrm{p}=0.000)$.

CONCLUSION: Index finger measurement was found to be almost equal to vertical dimension of occlusion, and maybe useful in determination of VDO.

KEY WORDS:Vertical dimension of occlusion, index finger, Prosthodontics, Oral Rehabilitation

HOW TO CITE: Hussain S, Yazdanie N. Correlation of the vertical dimension of occlusion with anthropometric measurement of index finger. J Pak Dent Assoc 2019;28(3):108-112.

DOI: https://doi.org/10.25301/JPDA.283.108

Received: 09 December 2018, Accepted: 19 June 2019

\section{INTRODUCTION}

I $\mathrm{n}$ prosthodontics treatment, the measurement of vertical dimension of occlusion (VDO) recording is considered an essential problem. ${ }^{1}$ This procedure is one of the key parameter to be established during the planning of oral rehabilitation; its determination is one of the most important stages of treatment since inadequate restoration can lead to the failure and disaster of prosthetic treatments. ${ }^{2}$

In a dentate patient, vertical jaw relation is the amount of separation between the maxilla and mandible, which can be further classified as rest vertical dimension and occlusal vertical dimension, when opposing teeth are not in occlusion and when teeth are in occlusion respectively. Mandibular Physiologic rest position is determined by muscles and gravity and not the teeth. ${ }^{3}$ Vertical dimension of occlusion is determined when the teeth comes in contact with each other. In case of patients with no natural teeth (edentulous patients), the procedure is determined when the dentures are occluded at correct VDO. ${ }^{4}$ The determination of occlusal vertical dimension is therefore, important both in edentulous and partially dentate patients. VDO may become inadequate in edentulous patient or partially dentate due to physiological

1. Assistant Professor, Department of Prosthodontics, Rehman College of Dentistry, RMI, Peshawar

2. Professor, Department of Prosthodontics, Principal Fatima Memorial Hospital College of Medicine Dentistry, Lahore.

Corresponding author: "Dr. Shafqat Hussain" <drshafqathussain86@gmail.com> or pathological process. ${ }^{5}$

When the OVD is lost, it not only effects the function but can also cause extra skin folds, increase in the depth of nasolabial furrows and changing the folds present at the angle of the mouth which may retain the saliva in these areas, leading to the angular chielitis. ${ }^{6}$ If there is increase in VDO during fabrication of a complete denture, it will decrease the interocclusal rest space which will lead to discomfort with the denture in mastication and speaking, incomplete muscle contraction, unaesthetic appearance due to elongation of face, teeth clicking and the most important resorption of alveolar ridge. ${ }^{7}$ It is therefore, important to correctly measure the VDO. There are a lot of advances in techniques and materials employed for recording vertical dimension of occlusion. In spite of the advances, one cannot rely on any single method for assessing vertical dimension of occlusion in patients who are completely edentulous. ${ }^{3}$

There are many methods which have been proposed for the determination of VDO that include the use of vertical dimension of rest (VDR), cephalometric radiographs, speech method, 2-points method, pre- extraction records etc. Though pre extraction records are easy, valuable and very accurate for restoring the VDO, they may not always be available. Scientifically speaking, none of the above methods have any proof of preference and almost every method has its limitations during its application in edentulous patients. ${ }^{7}$

McGee and Leonardo da Vinci correlated vertical 
dimension of occlusion with different measurements in the body parts. ${ }^{8}$ According to them original VDO is most of the time same as the measurement of the length of the distance between the outer canthus of one eye and the inner canthus of the other eye, size of the ear in vertical direction, twice the length of one eye, distance between the two pupils, and length of nose in vertical direction at the midline. When the sculptors and mathematicians used to follow the golden proportion of 1.618:1 in ancient time, the proportional of body parts were also determined by anthropometric measurements. ${ }^{4}$

Every method mentioned in the literature for determination of occlusal vertical dimension has some limitations. ${ }^{9}$ There is a dearth of published literature on this topic locally. It was therefore, the objective of this paper to study the correlation of the vertical dimension of occlusion with anthropometric measurement of index finger.

\section{METHODOLOGY}

A cross sectional study was conducted at Fatima Memorial Hospital College of Medicine and Dentistry, Lahore. The ethical approval for this study was obtained from institutional ethical committee (FMH-09-2018-IRB493-M). Sample size of 250 cases was calculated with $95 \%$ confidence level, 5\% type. I error, 10\% type II error and taking expected positive correlation between vertical dimension of occlusion and index finger. Non probability consecutive sampling technique was used. Our inclusion criteria was age range $=$ years, either gender, having normal occlusion as per operational definition, 28 fully erupted teeth and periodontal sound teeth assessed by clinical examination for mobility of teeth and gums recession. We excluded patients with open bite and deep bite, any dental anomaly, attrition/wear, assessed by clinical examination, extensive oral prosthesis or restorations, assessed by clinical examination, any extracapsular or intracapsular disorder of the Temporomandibular joint, or any other pathology in the maxillofacial region assessed by clinical examination, history of trauma, any previous Ortho treatment, heavy and bulky chin area (double chin), patients with neurological problems and patients Having deformity of fingers. Informed consent was taken from the patient before enrolling in the data collection procedure.

Demographic information like age and gender was recorded. Anthropometric measurements of vertical dimension of occlusion and length of index finger of right hand was recorded clinically in millimeters using a modified digital Vernier caliper with an accuracy of $0.01 \mathrm{~mm}$. To record VDO, the subjects was instructed to bite lightly on the posterior teeth with lips in repose and head well stabilized. The lower modified extended tip of caliper was placed firmly below the chin so that the soft tissues were compressed by pressure exerted and thus caliper coming as close as possible to the lower border of mandible against the skin. Now the upper tip of caliper was raised until it lightly touched the base of nasal septum and the measurement was made. Length of the index finger of right hand was measured on palmar aspect (in supination) from tip of finger to the near most point on palmar digital crease with digital caliper. The distance was then measured with digital Vernier caliper. While taking all these finger measurements it was made sure that nails of the subjects were trimmed. Average of 3 readings was taken in both measurements.

SPSS (version 17.0 for Windows) was used for the data entry and its statistical analysis. Descriptive statistics of vertical dimension of occlusion, length of index finger was performed and mean and standard deviation were calculated. A frequency distribution diagram was plotted for gender. The coefficient of correlation (r) between vertical dimension of occlusion and length of index finger was then calculated by Pearson's method. P-value of $\leq 0.05$ was considered as significant.

\section{RESULTS}

Descriptive statistics of the parameters studied were calculated and are presented in table 1 . The vertical dimension of occlusion was more in males as compared to

Table 1: Descriptive statistics of vertical dimension of occlusion, length of index finger

\begin{tabular}{|l|l|c|c|c|c|}
\hline \multicolumn{1}{|c|}{ Sex } & Measurements $(\mathrm{mm})$ & Mean(mm) & $\operatorname{SD}(\mathrm{mm})$ & Min(mm) & Max(mm) \\
\hline \multirow{2}{*}{ Male } & Age Of The Paticnt & 27.13 & 2.91 & 22.00 & 36.00 \\
\cline { 2 - 6 } & Vertical Dimension & 70.81 & 3.88 & 58.97 & 89.00 \\
\cline { 2 - 6 } & Index Finger & 70.92 & 3.62 & 58.97 & 76.84 \\
\hline \multirow{2}{*}{ Female } & Age Of The Paticnt & 27.43 & 3.84 & 22.00 & 36.00 \\
\cline { 2 - 6 } & Vertical Dimension & 61.32 & 4.23 & 52.65 & 71.23 \\
\cline { 2 - 6 } & Index Finger & 66.67 & 4.29 & 54.55 & 78.65 \\
\hline
\end{tabular}

\begin{tabular}{|l|c|c|}
\hline \multicolumn{1}{|c|}{ Gender } & Frequency & (\%) \\
\hline Male & 84 & 33.6 \\
\hline Female & 166 & 66.4 \\
\hline Total & 250 & 100.0 \\
\hline
\end{tabular}

Table 2: Distribution of study participants according to the gender 
females. Males had longer index finger as compared to females. The frequency distribution of study participants according to the gender is presented in table 2 . The diagram plotted is shown in figure 4. Gender specific correlations between vertical dimension of occlusion and length of index finger is presented in table 3 . The coefficient of correlation (r) by Pearson's method between the measured variables and vertical dimension of occlusion, at the probability level of $95 \%$ is presented. It was observed that in males and

Table 3: Gender specific correlations between vertical dimension of occlusion and length of index finger, length of little finger.

\begin{tabular}{|l|l|c|}
\hline \multirow{2}{*}{ Gender } & \multicolumn{2}{|l|}{ Index finger } \\
\hline \multirow{3}{*}{$\begin{array}{l}\text { Male } \\
\text { Vertical dimension (VDO) }\end{array}$} & $\mathrm{R}$ & $.745^{* *}$ \\
\cline { 2 - 3 } & $\mathrm{P}$-value & .000 \\
\cline { 2 - 3 } & $\mathrm{N}$ & 84 \\
\hline $\begin{array}{l}\text { Female } \\
\text { Vertical dimension (VDO) }\end{array}$ & $\mathrm{R}$ & $.819^{* *}$ \\
\cline { 2 - 3 } & $\mathrm{P}$-value & .000 \\
\cline { 2 - 3 } & $\mathrm{N}$ & 166 \\
\hline \multirow{4}{*}{$\begin{array}{l}\text { Female } \\
\text { Vertical dimension (VDO) }\end{array}$} & Little finger \\
\cline { 2 - 3 } & $\mathrm{R}$ & \multicolumn{2}{|l}{} \\
\cline { 2 - 3 } & $\mathrm{P}$-value & $.937^{* *}$ \\
\cline { 2 - 3 } & $\mathrm{N}$ & .000 \\
\hline
\end{tabular}

Table 4: Gender specific regression Analysis

\begin{tabular}{|l|l|c|l|c|c|}
\hline Sex & \multicolumn{1}{|c|}{$\begin{array}{c}\text { Dependent } \\
\text { Variable }\end{array}$} & $\begin{array}{c}\text { Independent } \\
\text { Variable }\end{array}$ & \multicolumn{1}{|c|}{$\begin{array}{c}\text { Regression } \\
\text { Equation }\end{array}$} & $\mathrm{R}^{2}(\%)$ & SE \\
\hline Male & VDO (Y) & A & A $=14.203+0.78$ & & \\
\hline Female & VDO (Y) & A & Y $=7.460+.808 \mathrm{~A}$ & 0.671 & \pm 2.43 \\
\hline Female & VDO (Y) & B & $\mathrm{Y}=9.567+0.85 \mathrm{~B}$ & 0.878 & \pm 2.48 \\
\hline
\end{tabular}

$\mathrm{A}=$ Index Finger, $\mathrm{B}=$ Little Finger. Regression Co-efficient significant at $\mathrm{p}<0.05$

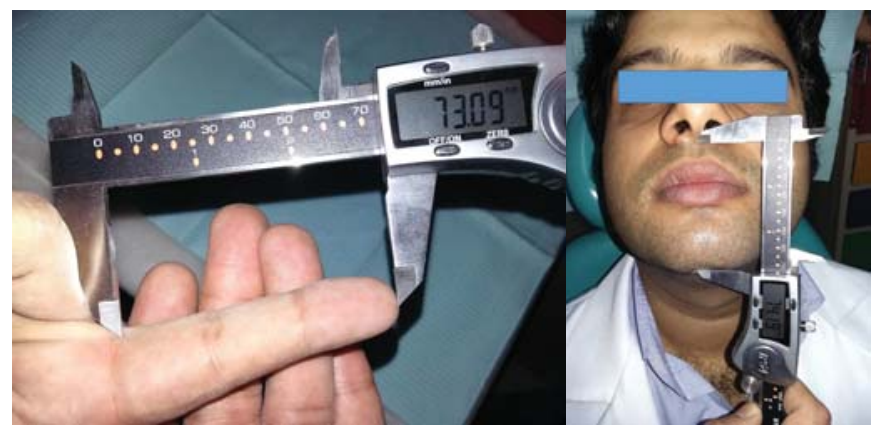

Fig 1: Measuring finger length

Fig 2: Measuring vertical dimension of occlusion

females, vertical dimension of occlusion is significantly and positively correlated with the length of index finger. In males, correlation of vertical dimension of occlusion for the parameter length of index finger was $r=0.74$. In females; correlation of vertical dimension of occlusion for the parameter length of index finger $r=0.82$.

\section{Gender Distribution of the study participants}

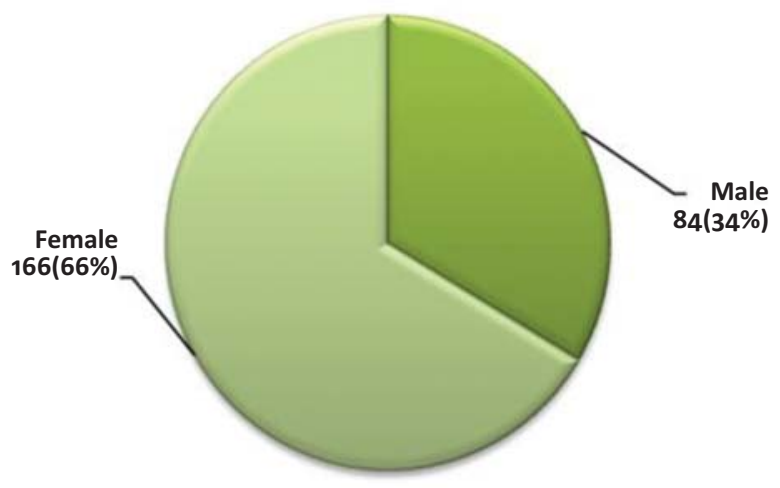

Fig 3: Gender distribution of study participants

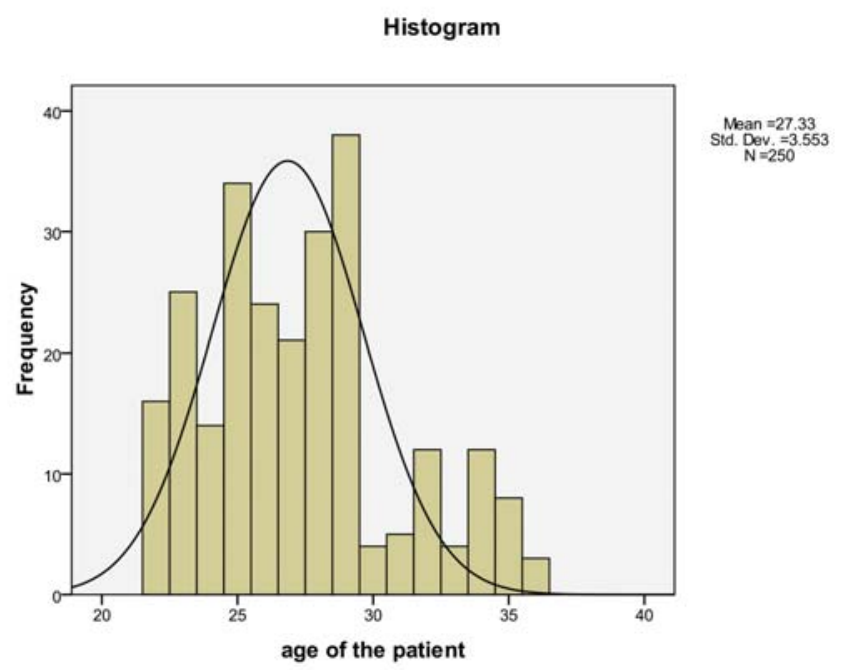

Fig 4: Age distribution of the study participants.

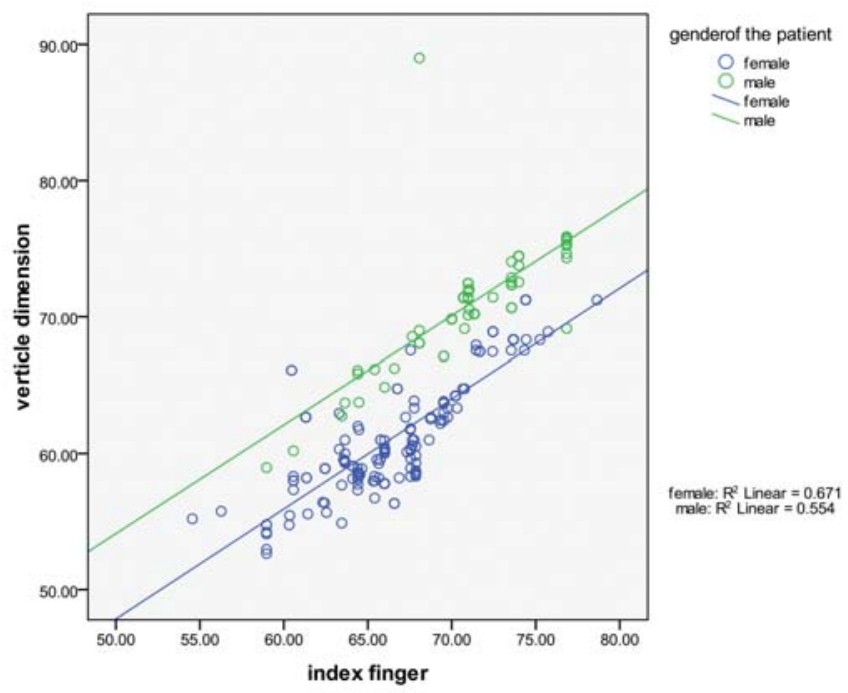

Fig 5: Scatter diagram along with regression lines of length of index finger versus vertical dimension of occlusion 
Gender specific regression analysis is presented in table4. We postulate following regression equations for use in patients

In males: Vertical dimension of occlusion $=14.20+$ $0.78 \times$ length of index finger

In females: Vertical dimension of occlusion $=7.46+$ $0.8 .8 \times$ length of index finger

\section{DISCUSSION}

Loss of teeth or the tooth structure can lead to functional, esthetics and psychological problems of the patients. During rehabilitation of the patient mouth, if the vertical dimensions of the face are changed, it may be sometime unacceptable to the patient until adapted. For this adaptation period, patients are given Provisionals with the intended occlusal vertical dimension at once or gradually. These Provisionals not only restore the esthetics and functions of the patient but also help in the adaptation of the patient to the prosthesis and the new OVD. The correct OVD is the key to the success of the new prosthesis or restoration.

Literature review suggest many different methods ${ }^{10-15}$ for determination of the vertical dimension of occlusion, that have been used in the field of dentistry for many years. Unfortunately, none of them is sole reliable method and every method employed has limitations and cannot be standardized in every patient. Niswonger's method ${ }^{16}$ can be effected by different variables. $\mathrm{McGee}^{8}$ stated that those methods which utilize patient's own perception for determining of the occlusal vertical dimension, can lead to reduced vertical dimension, as the patient feels more comfortable at the reduced vertical dimension. Silverman ${ }^{17}$ devised a method for the vertical dimension determination by incorporating tattoos in on the mucosa at the site of the teeth which were to be extracted in soon to be edentulous patients. Smith specified the bimeter method of Boos for recording the vertical dimension. ${ }^{18}$ However, the bimeter method has also many drawbacks as the patient has to use his power of closing which can be effected by pain and psychological state of the patient . Clinically it is observed that VDO varies in natural teeth in attrition cases and also when natural teeth contacts are lost and the Determination of the patient's vertical dimension becomes a matter of guesswork. ${ }^{7}$ So far speaking method, aesthetic evaluation and among pre-extraction records, methods like measurement of vertical and horizontal overlap of natural anterior teeth, are agreed to be the most reliable methods. ${ }^{17-}$ ${ }^{19}$ With no such records available, it is not possible to determine a starting point for the positioning of mandible to restore the occlusal vertical dimension.
To overcome these difficulties and considering the disadvantages of previously used methods, this study was undertaken to find a method which has the qualities of simplicity, practicality not only for the dentist but for the patient as well. In this study the relationship between VDO and length of index finger was correlated, taking into account that the growth of body parts takes place in proportion to each other. ${ }^{3}$ In this study, gender dimorphism was found, and it was found that the VDO values and the length of fingers were high in males as compared to females. These variations in finger length are because of the level of androgen exposure at puberty. ${ }^{20}$

The finger that were selected for measurements were that of right hand. Although there no differences between the lengths of fingers in right and left hands because of the symmetry of the body as stated by danborno, this will standardize the method of measurement. ${ }^{21}$ The mean values for the measured length of the index finger in males were $70.92 \mathrm{~mm}$ and in females this was $66.67 \mathrm{~mm}$. These values were very close to the research done by Danborno who showed a result of mean value of $71.54 \mathrm{~mm}$ in males and 68.65 in females. ${ }^{21}$

The results indicated that this method of VDO determination through measurement of index finger becomes a simple and basic guide. Moreover, this procedure is more of objective, than subjective, it gives more prosthetic advantage and minimize the guesswork in the procedure. The error in this method, of VDO estimation is within the range of 2-4 mm which is significantly less if we compare it to other methods which gives error in the range of $0-14 \mathrm{~mm} .{ }^{17,20}$ Slight differences during the measurement recording in the procedure those were found may be probably because of ethnicities difference, size of the sample or the difference in the method of measurement.

This study method is attractive and practical because it is simple, economical, non-invasive, reliable, requires no radiographs or sophisticated measuring devices, less time consuming and provides reproducible values for future reference. The study was limited to measurement of index finger only. Moreover, this study of correlation was only of length of the index finger and occlusal vertical dimension of occlusion, and, further research is required on the method by incorporating and studying different fingers and correlation with both the occlusal vertical dimension and rest vertical dimension.

\section{CONCLUSION}

Index finger measurement was found to be almost equal to vertical dimension of occlusion, and maybe useful in determination of VDO. 


\section{CONFLICT OF INTEREST}

None declared

\section{REFERENCES}

1. Rebibo M, Darmouni L, Jouvin J, Orthlieb J. Vertical dimension of occlusion: the keys to decision. Int j stomat occlus med. 2009;2:14759.

https://doi.org/10.1007/s12548-009-0027-7

2. Discacciati JAC, de Souza EL, Vasconcellos WA, Costa SC, de Magalhães Barros V. Increased vertical dimension of occlusion: signs, symptoms, diagnosis, treatment and options. J Contemp Dent Prac. 2013;14:123-28.

https://doi.org/10.5005/jp-journals-10024-1284

3. Naveen Raj T, Meshram A, Mulay S, Jethlia H. Review on methods of recording vertical relation. J Evolution Med Dent Sci. 2013; 2:19398

4. Ladda R, Bhandari AJ, Kasat VO, Angadi GS. A new technique to determine vertical dimension of occlusion from anthropometric measurements of fingers. Ind J Dent Res. 2013;24:316-20. https://doi.org/10.4103/0970-9290.117993

5. Bachhav V, Aras MA. Altering occlusal vertical dimension in functional and esthetic rehabilitation of severely worn dentition. J Oral Health Res. 2010.

6. Terms. GoP. Glossary of Prosthodontics Terms. 8th ed. J Prosthet Dent 2005;94:76.

7. Aruna B, Ladda R, Akshay B. Correlation between vertical dimension of occlusion and length of little finger. Pravara Med Rev. 2012;4:104.

8. Mcgee GF. Use of Facial Measurements in Determining Vertical Dimension. J Am Dent Assoc. 1947;35:9.

https://doi.org/10.14219/jada.archive.1947.0361

9. Shanahan TE. Physiologic vertical dimension and centric relation. J prosthet Dent. 2004;91:206-9.

https://doi.org/10.1016/j.prosdent.2003.09.002

10. Burnett C. Clinical rest and closest speech positions in the determination of occlusal vertical dimension. J oral rehab. 2000;27:7149.

https://doi.org/10.1046/j.1365-2842.2000.00561.x

11. Millet C, Jeannin C, Vincent B, Malquarti G. Report on the determination of occlusal vertical dimension and centric relation using swallowing in edentulous patients. J oral rehab. 2003;30:1118-22. https://doi.org/10.1046/j.1365-2842.2003.01201.x

12. Ahmed M. Accuracy and reliability of conventional methods in determining occlusal vertical dimension in a sample of Sudanese adults. Khartoum: U Khartoum. 2010
13. SMITH E. Importance and method of securing vertical dimension and centric relationships records in complete denture prosthesis. Lowa Dent Bulletin. 1948;34:12-5.

14. Timmer L. A reproducible method for determining the vertical dimension of occlusion. J Prosthet Dent. 1969;22:621-30. https://doi.org/10.1016/S0022-3913(69)80003-X

15. Morikawa M, Kozono Y, Noguchi BS, Yoyoda S. An additional attachment for a vertical dimension measuring device. J Prosthet Dent. 1990;64:117-8.

https://doi.org/10.1016/0022-3913(90)90158-9

16. Niswonger $M$. The rest position of the mandible and the centric relation. J Am Dent Assoc. 1934;21:1572-82.

https://doi.org/10.14219/jada.archive.1934.0258

17. Silverman MM. The speaking method in measuring vertical dimension. J Prosthet Dent. 2001;85:427-31.

https://doi.org/10.1067/mpr.2001.116139

18. Geerts G, Stuhlinger M, Nel D. A comparison of the accuracy of two methods used by pre-doctoral students to measure vertical dimension. J Prosthet Dent. 2004;91:59-66.

https://doi.org/10.1016/j.prosdent.2003.10.016

19. Johnson A, Wildgoose DG, Wood DJ. The determination of freeway space using two different methods. J Oral Rehabil. 2002;29:1010-3. Epub 2002/11/08.

https://doi.org/10.1046/j.1365-2842.2002.00950.x

20. Souza RFd, Compagnoni MA. Relation between speaking space of the/s/sound and freeway space in dentate and edentate subjects. Braz Oral Res. 2004;18:333-37.

https://doi.org/10.1590/S1806-83242004000400011

21. Delic Z, Šimunovic-Šoškic M, Perinic-Gržic R, Vukovojac S, Rajic Z, Kuna T, et al. Evaluation of craniometric methods for determination of vertical dimension of occlusion. Collegium antropologicum. 2000;24:31-5. 